\title{
Primary Cerebral Lymphoma: About 22 Cases with Literature Review
}

\author{
Adama Diakité*, Aphou Salle Koné, Idrissa Mama Diarra, Koniba Diabaté, \\ Tayeb Kebdani, Noureddine Benjaafar \\ Pôle de Radiothérapie Institut National d'Oncologie, CHU Ibn Sina, Rabat, Maroc \\ Email: *adamadoc@yahoo.fr
}

Received 17 June 2016; accepted 5 July 2016; published 8 July 2016

Copyright (c) 2016 by authors and Scientific Research Publishing Inc.

This work is licensed under the Creative Commons Attribution International License (CC BY).

http://creativecommons.org/licenses/by/4.0/

(c) (i) Open Access

\begin{abstract}
Primitive cerebral lymphoma (PCL) is a rare entity often poorly known. They are defined as extra nodal tumor interesting the CNS, brain and eye, and this in the absence of systemic lymphoma disease and brain metastases. The favoring factor is established immunosuppression which is explained by an increase in the incidence related to HIV. The basis of treatment is chemotherapy with consolidation radiotherapy. We report the experience of the National Institute of Oncology in Rabat in management of this disease.
\end{abstract}

\section{Keywords}

Primitive Cerebral Lymphoma, Chemotherapy, Radiotherapy

\section{Introduction}

The primitive cerebral lymphoma (PCL) is a rare entity often unclear; they are defined as lymph node tumors extra interesting CNS, meninges and the eye, and this in the absence of systemic lymphoma disease and brain metastases [1] [2]. They represent $1 \%-2 \%$ of Non-Hodgkin lymphoma (NHL), $4 \%$ of brain tumors and $4 \%$ $6 \%$ of extra nodal lymphoma. The encouraging factor is established immunosuppression which is explained by an increased incidence associated with HIV [3]. Treatment is based on consolidation chemotherapy with radiation therapy.

We report the experience of the National Oncology Institute in Rabat in the treatment of this pathology.

\section{Objectives}

Meet the epidemiological, clinical, histological, radiological and treatment of this pathology.

${ }^{*}$ Corresponding author.

How to cite this paper: Diakité, A., Koné, A.S., Diarra, I.M., Diabaté, K., Kebdani, T. and Benjaafar, N. (2016) Primary Cerebral Lymphoma: About 22 Cases with Literature Review. Journal of Cancer Therapy, 7, 500-504.

http://dx.doi.org/10.4236/jct.2016.77053 


\section{Patients and Methods}

This is a retrospective study of 22 cases of LCP collected at the National Oncology Institute in the period between 2004 and 2012 were included in this study all patients with positive biopsy of brain injury and in which the overall balance showed no systemic lymphoma disease or brain metastasis.

What were excluded from the study are patients without a positive biopsy, or with systemic lymphoma disease or brain metastasis.

\section{Results}

The average age of our population was $46 \pm 14$ years with a male predominance (63\%). The average time of consultation was 6 months ( $1-24$ mois). The first reason for consultation was the occurrence of headaches rebels and focal deficits. HIV status returned negative in 12 patients, positive in 3 patients and was not performed in 7 patients. All patients underwent a CT and/or MRI imaging magnetic resonance (torque CT and MRI in 11 patients) for the diagnosis of brain tumor. Histologically, all patients underwent stereotactic biopsy, diffuse large B-cell lymphoma was the most LCP (73\%). The small cell lymphoma B was found in 4 patients and 2 patients had a type of lymphoma $\mathrm{T}$. The treatment received was a CHOP-based chemotherapy in 18 patients and only 4 of our patients received methotrexate; Adjuvant radiotherapy was performed in 10 patients ( 30 Gy on total brain with an add on GTV 10 Gy). After a median follow up of 28 months ( 2 - 89) evolution was marked by the death of 8 patients, 9 are in good control and the other 5 were lost to view.

\section{Discussion}

PCL is a rare entity, it is $1 \%$ to $2 \%$ of non-Hodgkin lymphoma and $4 \%$ of all brain tumors; although the factor favoring established or immunosuppression, but an increased incidence observed in immunocompetent [3]. Most cases of PCL unrelated to HIV are diagnosed in patients between 45 and 70 years, with a median age at diagnosis around 50 years [4]. In HIV positive people, the average age is lower than 35 years [5].

The clinical symptomatology is polymorphous; in immunocompetent occurring mainly in the diagnosis a focal neurological deficit in $70 \%$ of cases, which is associated with alterations in mental status, signs of intracranial hypertension, and to a lesser extent a convulsive state and visual symptoms [6] [7].

The imaging typically include a monofocal or multifocal involvement in $25 \%$ of cases and supratentorial in $87 \%$ of cases (periventricular, thalamus, corpus callosum, basal ganglia); CT shows a rounded mass lesion taking the nonspecific appearance contrast, however, some elements draw attention to the particular lymphoma edema perished moderate lesion with low mass effect compared to tumor volume, intense contrast enhancement and homogeneous poorly defined edges and above the multiplicity and bilateral lesions; there are diffuse and infiltrative forms corresponding to hypodenses beaches brain parenchymal not taking the contrast, or as cortical opacities gyriformes; on brain MRI, the typical appearance of lymphoma is an expansive process although limited, periventricular, taking the contrast of intense and evenly, providing a look into "snowball" or "cotton". In general, the lesion is hypo or isosignal T2, surrounded by a more or less severe edema [5] [8].

The diagnosis of a PCL is a histological; when there is an eye tumor diagnosis may be cytological.

Stereotactic brain biopsy is the diagnostic method of choice and is essential especially for deep locations [9]-[11].

In $90 \%-95 \%$ of cases, histological diagnosis is a B cell lymphoma diffuse large cell, high grade [12] malignancy (73\% diffuse large B cell lymphoma cells in our series). Wherever possible, we must avoid any corticosteroids before performing brain biopsy that can be negated by a single outlet. However, corticosteroid therapy should be initiated immediately after the completion of the biopsy gesture; it would result in approximately $30 \%$ improvement and up to $10 \%$ complete response; conversely, if white biopsy, it is permissible to discuss the possibility of lymphoma when patients took corticosteroids [10].

After diagnosis of PCL general examination must be performed consistently with a HIV serology, complete eye examination and lumbar puncture (except in cases of threatening brain injury). The balance was not always thorough in our practice.

The differential diagnosis of primary brain lymphoma depends on the terrain: in immunocompetent be discussed astrocytic tumor if the lesion is isolated, meningioma in case of nodular lesions of the convexity and metastasis, abscess or forms nickname tumor sarcoidosis and multiple sclerosis if lesions are multifocal; in immunocompromised patients (AIDS), the main differential diagnosis is toxoplasmosis [5]. 
The therapeutic armamentarium includes chemotherapy, radiotherapy and steroids. Surgical excision is not indicated as causes no benefit in terms of survival [9].

One of the characteristics of the LCP is their cortico-sensitivity; corticosteroids induce apoptosis cell lymphomas and can cause significant regression of lesions LCP with clinical and radiological improvement; corticosteroids should be initiated only after a biopsy, because that can make it impossible to obtain a definitive diagnosis. Although the response to corticosteroids is not sustainable, it can mean a more favorable prognosis, with good survival for good responders [9] [13].

PCL are radiosensitive; RTH of the brain in total has been the standard for many years with an improved median survival of 10 - 18 months against 1.5 months without treatment. A retrospective study of 132 patients in Japan between 1990 and 1999, with a WHR of the brain at a dose of 40 Gy showed a median survival of 18 months, $39 \%$ survival at 2 years, and survival at 5 years $18 \%$ [14]. The radiation problem is its sometimes delayed neurotoxicity type dementia and ataxia. Combined with chemotherapy with methotrexate RTH would be responsible for a severe leukoencephalopathy [10]. RTH remains the standard consolidation therapy in patients less than 60 years.

Unlike systemic lymphoma, the treatment of cerebral lymphomas requires medication well through the blood brain barrier. LCP reference treatment remains intravenous chemotherapy with methotrexate based high doses $\left(>1-3 \mathrm{~g} / \mathrm{m}^{2}\right.$ ), usually associated with other molecules (cytarabine, etoposide, nitrosourés, vincristine, procarbazine, etc.) [15] in our series of chemotherapy used was CHOP in $82 \%$ of cases. Treatment with methotrexate is highly nephrotoxic, requiring intravenous hydration and prolonged monitoring in hospitals; among other side effects of chemotherapy, infectious complications are very common, especially in patients on prolonged corticosteroid or bedridden with cognitive disorders [10]. The chemosensitivity is high, with $45 \%$ to $60 \%$ complete response after induction chemotherapy [15]. It is considered that the response is complete when the contrast enhancement MRI disappeared while he persists in general Flair hyperintensity sequelae [10] [16]. Despite the good results Patients treated with CMT alone show many relapses hence the importance of adjuvant treatment.

There is a consensus that the combination regimen (chemoradiotherapy) is superior to other modalities [17] [18]. The treatment consists of a high dose of methotrexate based CMT associated with a consolidation by radiotherapy on total brain; This strategy is most commonly used for the treatment of LCP in immunocompetent patients; although this approach has significantly improved results in the management of LCP, it is still subject to a higher incidence of neurotoxicity, particularly in patients older than 60 years [19]-[21].

In our study 10 patients received the combined treatment and 8 of them are still in good control with acceptable neurotoxicity.

It nevertheless remains to elucidate questions to know what optimal dose of radiation? (Tendency to de-escalation), is it yes or no to the boost? Should radiate so complete response after chemotherapy?

However, relapses are very common, occurring on average after six to ten months in the elderly [10]. In $90 \%$ of cases, relapse is cerebral, locally or remotely, uni- or multi-focal; in $10 \%$ to $20 \%$ of cases, it is ocular and systemic that is in $5 \%$ to $10 \%$ of cases. Several clinical and molecular prognostic factors are recognized: the young, a good initial clinical status, early and complete response to treatment are associated with prolonged survival [10] [22], while the loss of 6q chromosome rearrangements BCL6 is associated with a poor prognosis [10] [23].

The overall prognosis is poor with a median survival of about 30 to 60 months [15], which reaches 15 to 35 months in patients over 60 years. Nevertheless there $20 \%$ to $30 \%$ of long-term survivors ( $>5$ years) and healing has become a focus of treatment. In our series we have 2 long survivors with respectively 83 months and 89 months of decline.

\section{Conclusion}

The PCL is a rare tumor. In the absence of randomized chemoradiotherapy, it remains the standard treatment in patients under 60 years. The challenge remains the management of neurological toxicity and improved patient survival.

\section{Conflict of Interest}

The authors report no conflict of interest. 


\section{References}

[1] Paulus, W. (1999) Classification, Pathogenesis and Molecular Pathology of Primary CNS Lymphomas. Journal of Neuro-Oncology, 43, 203-208. http://dx.doi.org/10.1023/A:1006242116122

[2] Sheibani, K., Battifora, H., Winberg, C.D. and Burke, J.S., et al. (1986) Further Evidence that Malignant Angioendotheliomatosis' Is an Angiotropic Large-Cell Lymphoma. The New England Journal of Medicine, 314, 943-948. http://dx.doi.org/10.1056/NEJM198604103141502

[3] Olson, J.E. (2002) The Continuing Increase in the Incidence of Primary Central Nervous System Non-Hodgkin Lymphoma: A Surveillance, Epidemiology, and End Results Analysis. Cancer, 95, 1504-1510.

[4] Villano, J.L., Koshy, M., Shaikh, H., Dolecek, T.A. and McCarthy, B.J. (2011) Age, Gender, and Racial Differences in Incidence and Survival in Primary CNS Lymphoma. British Journal of Cancer, 195, 1414-1418.

[5] Gondry-Jouet, C., Demasure, F., Le Bars, E., Toussaint, P., Roubertou, H. and Deramond, H. (1999) Tumeurs hémisphériques intracrâniennes. Encyclopédie Médicale et Chirurgicale, Radiodiagnostic Neuroradiologie-Appareil locomoteur, 31-658-A-10.

[6] Bataille, B., Delwail, V., Menet, E., et al. (2000) Primary Intracerebral Malignant Lymphoma: Report of 248 Cases. Journal of Neurosurgery, 92, 261-266.

[7] Bauchet, L., Rigau, V., Mathieu-Daudé, H., Figarella-Branger, D., et al. (2007) French Brain Tumor Data Bank: Methodology and First Results on 10,000 Cases. Journal of Neurosurgery, 84, 189-199. http://dx.doi.org/10.1007/s11060-007-9356-9

[8] Buhring, U., Herrlinger, U., Krings, T., et al. (2001) MRI Features of Primary Central Nervous System Lymphomas at Presentation. Neurology, 57, 394-396. http://dx.doi.org/10.1212/WNL.57.3.393

[9] Hoang-Xuan, K., Napolitano, M., Cornu, P. and Delattre, J.Y. (1999) Traitement des lymphomes cérébraux primitifs. Encyclopédie Médicale et Chirurgicale(Paris: Elsevier), Neurologie, 17-270-A-15.

[10] Houillier, C., Gonzalez-Aguilar, A. and Hoang-Xuan, K. (2012) Lymphome cérébral primitif chez un sujet immunocompétent. Pratique Neurologique —FMC, 3, 40-44. http://dx.doi.org/10.1016/j.praneu.2011.12.005

[11] Benouaich, A. (2002) Lymphomes primitifs du système nerveux central chez le sujet immunocompétent. Eurocancer 2002, John Libbey Eurotext, Paris $($, 103-106.

[12] Ferreri, A.J.M. and Marturano, E. (2012) Primary CNS lymphoma. Best Practice \& Research: Clinical Haematology, 25, 119-130. http://dx.doi.org/10.1016/j.beha.2011.12.001

[13] Mathew, B.S., Carson, K.A. and Grossman, S.A. (2006) Initial Response to Glucocorticoids. Cancer, 106, $383-387$.

[14] Shibamoto, Y., Ogino, H., Hasegawa, M., et al. (2005) Results of Radiation Monotherapy for Primary Central Nervous System Lymphoma in the 1990s. International Journal of Radiation Oncology * Biology * Physics, 62, 809-813.

[15] Ferreri, A.J., Reni, M., Foppoli, M., Martelli, M., Pangalis, G.A., Frezzato, M., et al. (2009) High-Dose Cytarabine plus High-Dose Methotrexate versus High-Dose Methotrexate Alone in Patients with Primary CNS Lymphoma: A Randomised Phase 2 Trial. The Lancet, 374, 1512-1520. http://dx.doi.org/10.1016/S0140-6736(09)61416-1

[16] Abrey, L.E., Batchelor, T.T., Ferreri, A.J., Gospodarowicz, M., et al. (2005) Report of an International Workshop to Standardize Baseline Evaluation and Response Criteria for Primary CNS Lymphoma. Journal of Clinical Oncology, 23, 5034-5043. http://dx.doi.org/10.1200/JCO.2005.13.524

[17] Ferreri, A.J., Reni, M. and Villa, E. (2000) Therapeutic Management of Primary Central Nervous System Lymphoma: Lessons from Prospective Trials. Annals of Oncology, 11, 927-937. http://dx.doi.org/10.1023/A:1008376412784

[18] Deangelis, L.M., Seiferheld, W., Schold, S.C., Fisher, B. and Schultz, C.J. (2002) Combination Chemotherapy and Radiotherapy for Primary Central Nervous System Lymphoma: Radiation Therapy Oncology Group Study 93-10. Journal of Clinical Oncology, 20, 4643-4648. http://dx.doi.org/10.1200/JCO.2002.11.013

[19] Ferreri, A.J., Abrey, L.E., Blay, J.Y., et al. (2003) Summary Statement on Primary Central Nervous System Lymphomas. The 8th International Conference on Malignant Lymphoma, Lugano, 12-15 June 2002, 2407-2414. http://dx.doi.org/10.1200/JCO.2003.01.135

[20] Poortmans, P.M., Kluin-Nelemans, H.C., Haaxma-Reiche, H., et al. (2003) High Dose Methotrexate Based Chemotherapy Followed by Consolidating Radiotherapy in Non-AIDS Related Primary Central Nervous System Lymphoma: European Organization for Research and Treatment of Cancer Lymphoma Group Phase II Trial 20962. Journal of Clinical Oncology, 21, 4483-4488. http://dx.doi.org/10.1200/JCO.2003.03.108

[21] Abrey, L.E., Yahalom, J. and Deangelis, L.M. (2000) Treatment for Primary CNS Lymphoma: The Next Step. Journal of Clinical Oncology, 18, 3144-3150.

[22] Abrey, L.E., Ben-Porat, L., Panageas, K.S., Yahalom, J., et al. (2006) Primary Central Nervous System Lymphoma: The Memorial Sloan-Kettering Cancer Center Prognostic Model. Journal of Clinical Oncology, 24, 5711-5715. http://dx.doi.org/10.1200/JCO.2006.08.2941 
[23] Cady, F.M., O’Neill, B.P., Law, M.E., Decker, P.A., et al. (2008) Del(6)(q22) and BCL6 Rearrangements in Primary CNS Lymphoma Are Indicators of an Aggressive Clinical Course. Journal of Clinical Oncology, 26, 4814-4819. http://dx.doi.org/10.1200/JCO.2008.16.1455

Submit or recommend next manuscript to SCIRP and we will provide best service for you:

Accepting pre-submission inquiries through Email, Facebook, Linkedin, Twitter, etc A wide selection of journals (inclusive of 9 subjects, more than 200 journals)

Providing a 24-hour high-quality service

User-friendly online submission system

Fair and swift peer-review system

Efficient typesetting and proofreading procedure

Display of the result of downloads and visits, as well as the number of cited articles

Maximum dissemination of your research work

Submit your manuscript at: http://papersubmission.scirp.org/ 